\title{
Metabolic Profile and Insulin Resistance in Different Phenotypes of Polycystic Ovary Syndrome Attending in a Tertiary Care Hospital of Bangladesh
}

\author{
Mohammad Afjal Hossain ${ }^{1}$, Milton Barua ${ }^{2, ~ *, ~ M i r z a ~ S h a r i f u z z a m a n ~}{ }^{3}$, Farzana Amin ${ }^{4}$, Lutful Kabir ${ }^{5}$, \\ Nusrat Mahmud ${ }^{6}$, Faria Afsana ${ }^{7}$, Faruque Pathan ${ }^{7}$, Mahmudul Kabir ${ }^{7}$, Mahmudul Islam Talukder ${ }^{8}$, \\ Amanat Ullah ${ }^{9}$ \\ ${ }^{1}$ Department of Endocrinology, US- Bangla Medical College, Narayanganj, Bangladesh \\ ${ }^{2}$ Department of Medicine, Endocrinology \& Diabetes, Chittagong General Hospital, Chittagong, Bangladesh \\ ${ }^{3}$ Department of Endocrinology, Dhaka Medical College, Dhaka, Bangladesh \\ ${ }^{4}$ Department of Obstetrics and Gynaecology, South East Model Hospital, Dhaka, Bangladesh \\ ${ }^{5}$ Department of Endocrinology, Rangpur Medical College, Rangpur, Bangladesh \\ ${ }^{6}$ Department of Obstetrics and Gynaecology, BIRDEM General Hospital, Dhaka, Bangladesh \\ ${ }^{7}$ Department of Endocrinology, BIRDEM General Hospital, Dhaka, Bangladesh \\ ${ }^{8}$ Department of Medicine, Dhaka Medical College, Dhaka \\ ${ }^{9}$ Acute Medicine, Medway Maritime Hospital, Gillingham, Kent, UK
}

Email address:

dr.miltonbarua@gmail.com (M. Barua)

${ }^{*}$ Corresponding author

To cite this article:

Mohammad Afjal Hossain, Milton Barua, Mirza Sharifuzzaman, Farzana Amin, Lutful Kabir, Nusrat Mahmud, Faria Afsana, Faruque Pathan, Mahmudul Kabir, Mahmudul Islam Talukder, Amanat Ullah. Metabolic Profile and Insulin Resistance in Different Phenotypes of Polycystic Ovary Syndrome Attending in a Tertiary Care Hospital of Bangladesh. International Journal of Diabetes and Endocrinology. Vol. 6, No. 3, 2021, pp. 88-94. doi: 10.11648/j.ijde.20210603.11

Received: April 11, 2021; Accepted: June 15, 2021; Published: June 30, 2021

\begin{abstract}
Background: Polycystic ovary syndrome (PCOS) is a common endocrine disorder associated with various phenotypic expressions. Aims: This study was conducted to observe and compare various metabolic components in different phenotypes of PCOS and to find out the frequency of insulin resistance (IR) among them. Materials and Methods: Eighty (80) patients diagnosed as case of PCOS as per inclusion and exclusion criteria were recruited in this cross sectional observational study. Patients were categorized in 4 different phenotypes based on the presence of oligo/anovulation $(\mathrm{O})$, hyperandrogenism $(\mathrm{H})$ and polycystic ovarian morphology (P): (i) Phenotype A $(\mathrm{O}+\mathrm{H}+\mathrm{P})$, Phenotype B $(\mathrm{O}+\mathrm{H})$, (iii) Phenotype $\mathrm{C}(\mathrm{H}+\mathrm{P})$ and (iv) Phenotype D $(\mathrm{O}+\mathrm{P})$. Demographic, anthropometric, biochemical and metabolic parameters were recorded and compared by ANOVA \& Chi Square test using SPSS software version 22.0. Results: Most prevalent phenotype was phenotype A (55\%) followed by phenotype D (22.5\%), phenotype B (15\%) \& phenotype C (7.5\%). Phenotype A \& B had higher mean body mass index (BMI), waist circumference (WC), waist hip ratio (WHR), total testosterone (TT), fasting insulin, triglycerides (TG) \& lower HDL-cholesterol in comparison to phenotype C \& D (P value 0.001, 0.000, 0.000, 0.003, 0.000, $0.005 \& 0.046$ respectively). Fasting plasma glucose (FPG), plasma glucose 2 hours after 75 grams oral glucose load (AG), total cholesterol \& LDL-cholesterol were comparable among the phenotypes ( $\mathrm{P}$ value $0.636,0.829,0.143 \& 0.201$ respectively). Overall frequency of IR as defined by HOMA-IR $\geq 3.8$ was $61.25 \%$. Highest frequency of IR was found in phenotype B followed by phenotype A and least in phenotype D (IR in A, B, C \& D were $72.73 \%$, $83.33 \%, 33.33 \% \& 27.28 \%$, P 0.002). Conclusion: Phenotype A \& B had higher degree of deranged metabolic parameters than other phenotypes. Insulin resistance is mostly associated with phenotype A \& B and least in normoandrogenic phenotype (phenotype D).
\end{abstract}

Keywords: Polycystic Ovary Syndrome, Phenotype, Metabolic Profile, Insulin Resistance 


\section{Introduction}

Polycystic ovary syndrome (PCOS) is a heterogenous disorder mainly affecting the female of reproductive age. Prevalence of PCOS varies with different diagnostic criteria. Overall prevalence of PCOS is $5 \%$ to $20 \%$ globally. [1] 1990 National Institutes of Health (NIH) criteria and Revised Rotterdam Consensus 2003 criteria are widely used for diagnosis of PCOS. [2, 3] NIH criteria included both clinical and/or biochemical hyperandrogenism and chronic anovulation for diagnosis of PCOS where Rotterdam criteria suggested that PCOS should be diagnosed by two of the following three features: oligo-anovulation, clinical or biochemical hyperandrogenism and polycystic ovaries (PCO) on ultrasound after excluding other related disorders. According to Revised Rotterdam Consensus 2003 criteria PCOS patients can be divided in four phenotypes: phenotype A (NIH PCOS of biochemical/clinical hyperandrogenism and oligo/anovulation with PCO); phenotype B (NIH PCOS of biochemical/clinical hyperandrogenism and oligo/anovulation without $\mathrm{PCO}$ ); phenotype $\mathrm{C}$ (non-NIH PCOS with biochemical/clinical hyperandrogenism and PCO but with normal ovulation); phenotype D (non-NIH PCOS with oligo/anovulation and PCO but without any biochemical/clinical hyperandrogenism). [4]

It is well established that women with PCOS have an increased risk of insulin resistance (IR) and hyperinsulinemia, an increased risk of glucose intolerance and type 2 diabetes mellitus, dyslipidemia, subclinical atherosclerosis, and vascular dysfunction, independent of body mass index (BMI). [5] Insulin resistance may play a significant role in development of PCOS and its metabolic complications. [6-9] Prevalence of insulin resistance among PCOS subjects may varies from $44 \%$ to $70 \%$ worldwide. [7, 10] However, there are controversies on presence of IR in different phenotypes of PCOS. Most of the studies to observe metabolic profile and insulin resistance were done where hyperandrogenic patients with PCOS were mostly included. Very few study suggested newer phenotypes-hyperandrogenism plus polycystic ovaries plus normal ovulatory cycles (phenotype C) and anovulation and polycystic ovaries without hyperandrogenism (phenotype D) show little or no evidence of IR using surrogate markers. [7] In spite of these studies, there are limited data on metabolic features and IR in women belonging to the newer phenotypes created by the Rotterdam criteria, especially normoandrogenic phenotype of PCOS. [11] This study was done to observe and compare various metabolic components and insulin resistance in the phenotypes of PCOS in Bangladesh.

\section{Materials and Methods}

This cross sectional observational study was conducted over the period of 13 (thirteen) months, dated from April-2016 to April-2017 at Endocrinology and Obstetrics \& Gynaecology OPD in Bangladesh Institute of Research and Rehabilitation in
Diabetes, Endocrine and Metabolic Disorders (BIRDEM General Hospital). Ethical clearance was taken from the Institutional Review Board of BIRDEM. PCOS patients were diagnosed on the basis of Revised Rotterdam Consensus 2003 criteria. Patients who refused to take part in the study or patients with chronic diseases or taking medications which may alter clinical or biochemical parameters including corticosteroids, oral contraceptives, estrogen, anti-androgen, metformin, lipid lowering agents or drugs affecting glucose metabolism and pregnant women were excluded. Eighty (80) untreated patients with PCOS aged 18 to 43 years were selected for the study by purposive sampling technique as per inclusion and exclusion criteria. Demographic, anthropometric $\&$ clinical data of the patient were recorded in a data collection sheet after obtaining informed written consent. Height, weight, waist circumference (WC), hip circumference (HC) was measured using calibrated instruments by investigators or female colleague or trained nurse when needed. Transabdominal (in unmarried) or transvaginal (in married) ultrasonography was performed preferably in early follicular phase. Blood samples for hormonal analysis were collected on second to seventh day of menstruation or at any time in case of amenorrhoea. Hormones including total testosterone and fasting insulin were measured by chemiluminescent microparticle immunoassay (CMIA) system using ARCHITECT PLUS i 1000 SR, ABBOTT (Germany). Venous plasma for glucose were measured after overnight fast and after 75 grams oral glucose load by Colourimetric method (Glucose 6 phosphate dehydrogenase) using ADVIA 1800, SIEMENS (USA). Fasting lipid profile was measured after overnight fast. Total Cholesterol, LDL cholesterol and HDL cholesterol were measured by oxidase method using ADVIA 1800, SIEMENS (USA). Triglyceride (TG) was measured by Enzymetric method (dehydrogenase) using ADVIA 1800, SIEMENS (USA).

According to Revised Rotterdam Consensus 2003 criteria, PCOS is diagnosed if at least two of the following criteria are present: oligo/anovulation (defined as delayed menses $>35$ days or $<8$ spontaneous hemorrhagic episodes/year), clinical hyperandrogenism (hirsutism using modified FerrimanGallway score of $\geq 8$ ) or biochemical hyperandrogenism (total testosterone level elevated than reference cut off value $0.9 \mathrm{ng} / \mathrm{ml}$ ) and polycystic ovarian morphology on ultrasonography (12 or more follicles in any ovary measuring 2-9 $\mathrm{mm}$ in diameter, and/or increased ovarian volume $(\geq 10$ $\mathrm{cm}^{3}$ ) with exclusion of other related disorders. [3, 12] After diagnosis, women with PCOS were divided into four phenotypes, based on the presence of oligo-anovulation (O), hyperandrogenism $(\mathrm{H})$ and polycystic ovarian morphology (P): (i) Phenotype A $(\mathrm{O}+\mathrm{H}+\mathrm{P})$, (ii) Phenotype $\mathrm{B}(\mathrm{O}+\mathrm{H})$, (iii) Phenotype $\mathrm{C}(\mathrm{H}+\mathrm{P})$ and (iv) Phenotype D $(\mathrm{O}+\mathrm{P})$. [4]

Any degree of glucose intolerance was diagnosed as American Diabetes Association (ADA) criteria, 2016. [13] According to the ADA 2016, normal glucose tolerance (NGT) was diagnosed when fasting plasma glucose $(\mathrm{FPG})<5.6$ $\mathrm{mmol} / \mathrm{L} \&$ plasma glucose level 2-hour after 75 grams 
glucose load (AG) $<7.8$ mmol/L; Impaired Fasting Glucose (IFG) was diagnosed when fasting plasma glucose (FPG) was between 5.6-6.9 mmol/L \& plasma glucose level 2-hour after 75 grams glucose load $(\mathrm{AG})<7.8 \mathrm{mmol} / \mathrm{L}$, and Impaired Glucose Tolerance (IGT) was diagnosed when the 2-h Plasma Glucose (AG) value during a $75 \mathrm{~g}$ Oral Glucose Tolerance Test (OGTT) was between 7.8-11.0 mmol/L where FPG $<7 \mathrm{mmol} / \mathrm{L}$. Diabetes mellitus was diagnosed when FPG $\geq 7.0 \mathrm{mmol} / \mathrm{L}$, and AG value during a $75 \mathrm{~g}$ OGTT of $\geq 11.1$ $\mathrm{mmol} / \mathrm{L}$. Dyslipidemia was diagnosed when one or more of the following value was present in Fasting Lipid Profile: Total cholesterol $>200 \mathrm{mg} / \mathrm{dl}$, TG $>150 \mathrm{mg} / \mathrm{dl}$, LDL-C $>$ $130 \mathrm{mg} / \mathrm{dl}$, HDL-C $<50 \mathrm{mg} / \mathrm{dl}$. [14] Insulin resistance (IR) was diagnosed on the basis of Homeostatic model assessment of insulin resistance (HOMA-IR) $\geq 3.8$. HOMA-IR was calculated using the formula, HOMA-IR=fasting glucose $(\mathrm{mmol} / \mathrm{L}) \times$ fasting insulin $(\mu \mathrm{U} / \mathrm{ml}) / 22.5$. [15]

After collection, data were checked for inadequacy, irrelevancy, and inconsistency. Irrelevant data were discarded. After editing and coding, the coded data was directly entered into the computer by using Statistical Package for the Social Sciences (SPSS) software, version 22.0. Quantitative variables were expressed as mean \pm standard deviation (SD) and were compared between groups using one way analysis of variance (ANOVA) with Tukey HSD post hoc test in appropriate cases. Qualitative variables were expressed as frequencies in percentages and were analyzed by $\chi 2$ test. A $P$ value of less than 0.05 was considered statistically significant.

\section{Results}

Total 80 (Eighty) PCOS cases were included in the study. Mean age of study sample was $24.94 \pm 5.51$ years and most of the cases (67) were below 30 years of age. Range of BMI in study subjects was 17.6 to $43.80 \mathrm{~kg} / \mathrm{m}^{2}$. Mean BMI was $26.55 \pm 5.30 \mathrm{~kg} / \mathrm{m}^{2}$ and most of the subjects (57) were either overweight or obese (total overweight \& obese $71.25 \%$ when $\mathrm{BMI} \geq 23 \mathrm{~kg} / \mathrm{m}^{2}$ ). Mean WC and WHR were $92.13 \pm 11.43 \mathrm{~cm}$ and $0.93 \pm 0.08$ respectively.

Table 1 shows distribution of different phenotypes of PCOS which indicates phenotype A (55\%) and D (22.5\%) were most frequent phenotypes in these study subjects where phenotype C (7.5\%) was least frequent.

Table 1. Distribution of different PCOS phenotypes.

\begin{tabular}{lllll}
\hline \multirow{2}{*}{ Characteristics } & \multicolumn{7}{l}{ Phenotypes } & B & C & D \\
\cline { 2 - 5 } & A & B & & \\
Oligo/anovulation & + & + & - & + \\
Hyperandrogenism & + & + & + & - \\
Polycystic ovarian & + & - & + & + \\
morphology & & & & \\
Frequency & $44(55 \%)$ & $12(15 \%)$ & $6(7.5 \%)$ & $18(22.5 \%)$ \\
\hline
\end{tabular}

Table 2 shows comparison of different demographic, anthropometric and metabolic characteristics among PCOS phenotypes. Phenotype A \& B had higher body mass index (BMI), waist circumference (WC) and waist hip ratio (WHR) in comparison to phenotype C \& D (BMI: 28.18 \pm 4.96 , $27.51 \pm 6.12,25.63 \pm 3.96 \& 22.23 \pm 3.45 \mathrm{~kg} / \mathrm{m}^{2}, P$ value 0.000 ; WC: $96.41 \pm 10.23,93.17 \pm 12.99,87.00 \pm 10.26 \& 82.67 \pm 7.08$ $\mathrm{cm}, P$ value 0.000 ; WHR: $0.97 \pm 0.07,0.94 \pm 0.08,0.90 \pm 0.08$ $\& 0.86 \pm 0.05, P$ value 0.000 respectively). Fasting plasma glucose (FPG) and plasma glucose 2 hours after 75 grams oral glucose load (AG) were comparable among the phenotypes (FPG: $5.47 \pm 1.27, \quad 5.71 \pm 0.91, \quad 5.35 \pm 1.12$ \& $5.14 \pm 1.22 \mathrm{mmol} / \mathrm{L}, P$ value 0.636 and $\mathrm{AG}: 7.98 \pm 3.07$, $8.20 \pm 3.19,7.72 \pm 3.06 \& 7.29 \pm 2.54 \mathrm{mmol} / \mathrm{L}, P$ value 0.829 respectively).

Table 2. Comparison of different clinical and metabolic characteristics among PCOS phenotypes.

\begin{tabular}{|c|c|c|c|c|c|}
\hline Variables & A (44) & B (12) & $\mathrm{C}(06)$ & D (18) & $P$ value \\
\hline Age (years) & $24.84 \pm 5.14$ & $25.67 \pm 6.21$ & $24.50 \pm 5.47$ & $24.83 \pm 6.35$ & 0.967 \\
\hline $\mathrm{BMI}(\mathrm{Kg} / \mathrm{m} 2)$ & $28.18 \pm 4.96 \mathrm{~d}$ & $27.51 \pm 6.12 \mathrm{~d}$ & $25.63 \pm 3.96$ & $22.23 \pm 3.45 \mathrm{ab}$ & 0.000 \\
\hline $\mathrm{WC}(\mathrm{cm})$ & $96.41 \pm 10.23 d$ & $93.17 \pm 12.99 \mathrm{~d}$ & $87.00 \pm 10.26$ & $82.67 \pm 7.08 \mathrm{ab}$ & 0.000 \\
\hline WHR & $0.97 \pm 0.07 d$ & $0.94 \pm 0.08 \mathrm{~d}$ & $0.90 \pm 0.08$ & $0.86 \pm 0.05 \mathrm{ab}$ & 0.000 \\
\hline SBP (mm Hg) & $120.23 \pm 16.17 \mathrm{~d}$ & $120.42 \pm 17.38$ & $109.17 \pm 18.55$ & $107.22 \pm 14.06 \mathrm{a}$ & 0.021 \\
\hline DBP (mm Hg) & $76.14 \pm 10.67$ & $80.00 \pm 11.08$ & $71.67 \pm 10.33$ & $71.67 \pm 10.00$ & 0.149 \\
\hline Total Testosterone $(\mathrm{ng} / \mathrm{ml})$ & $0.86 \pm 0.24 \mathrm{~d}$ & $0.86 \pm 0.22 \mathrm{~d}$ & $0.79 \pm 0.26$ & $0.61 \pm 0.20 \mathrm{ab}$ & 0.003 \\
\hline LDL-C (mg/dl) & $119.77 \pm 27.85$ & $121.58 \pm 28.81$ & $116.17 \pm 18.88$ & $104.94 \pm 20.18$ & 0.201 \\
\hline HDL-C (mg/dl) & $40.73 \pm 10.86 \mathrm{~d}$ & $42.58 \pm 9.28$ & $43.83 \pm 12.46$ & $49.44 \pm 11.02 \mathrm{a}$ & 0.046 \\
\hline Triglyceride (TG) (mg/dl) & $147.05 \pm 70.86 \mathrm{~d}$ & $146.50 \pm 65.84 d$ & $136.33 \pm 86.58$ & $81.33 \pm 34.35 \mathrm{ab}$ & 0.005 \\
\hline $\mathrm{FPG}(\mathrm{mmol} / \mathrm{L})$ & $5.47 \pm 1.27$ & $5.71 \pm 0.91$ & $5.35 \pm 1.12$ & $5.14 \pm 1.22$ & 0.636 \\
\hline $\mathrm{AG}(\mathrm{mmol} / \mathrm{L})$ & $7.98 \pm 3.07$ & $8.20 \pm 3.19$ & $7.72 \pm 3.06$ & $7.29 \pm 2.54$ & 0.829 \\
\hline Fasting insulin $(\mu \mathrm{IU} / \mathrm{ml})$ & $23.34 \pm 9.33 d$ & $25.18 \pm 8.37 d$ & $16.12 \pm 10.60$ & $13.45 \pm 6.87 \mathrm{ab}$ & 0.000 \\
\hline GIR & $5.22 \pm 3.48 \mathrm{~d}$ & $4.39 \pm 1.23 \mathrm{~d}$ & $7.78 \pm 3.63$ & $8.06 \pm 3.05 \mathrm{ab}$ & 0.003 \\
\hline
\end{tabular}

*BMI=Body mass index, WC=Waist circumference, WHR=Waist hip ratio, $\mathrm{SBP}=\mathrm{Systolic}$ blood pressure, $\mathrm{DBP}=\mathrm{Diastolic}$ blood pressure, $\mathrm{FPG}=\mathrm{Fasting}$ plasma glucose, GIR=fasting glucose to fasting insulin ratio, HOMA-IR=Homeostatic model assessment of insulin resistance

${ }^{* *} P$ value $<0.05$ indicates statistically significant difference among phenotypes. a, b, c, d indicates significant difference in comparison to phenotypes A, B, $\mathrm{C}$ and D.

Higher triglycerides (TG) and lower high density lipoprotein cholesterol (HDL-C) were found in phenotypes A and B compared to phenotypes C \& D where total cholesterol (TC) and low density lipoprotein cholesterol (LDL-C) were 
comparable among the phenotypes (TG: 147.05 \pm 70.86 , $146.50 \pm 65.84,136.33 \pm 86.58 \& 81.33 \pm 34.35 \mathrm{mg} / \mathrm{dl} P$ value 0.005 ; HDL-C: $40.73 \pm 10.86,42.58 \pm 9.28,43.83 \pm 12.46 \&$ $49.44 \pm 11.02 \mathrm{mg} / \mathrm{dl}, P$ value $0.046 ;$ TC: $189.95 \pm 33.11$, $193.59 \pm 34.34,187.33 \pm 32.95 \& 170.67 \pm 25.35 \mathrm{mg} / \mathrm{dl}, \mathrm{P}$ value 0.143 ; LDL-C: $119.77 \pm 27.85,121.58 \pm 28.81,116.17 \pm 18.88$ $\& 104.94 \pm 20.18 \mathrm{mg} / \mathrm{dl}, P$ value 0.201 respectively). Fasting insulin was higher in phenotypes A \& B compared to phenotypes C \& D $(23.34 \pm 9.33,25.18 \pm 8.37,16.12 \pm 10.60$ \& $13.45 \pm 6.87 \mu \mathrm{IU} / \mathrm{ml} P$ value 0.000$)$. HOMA-IR was highest in phenotype $\mathrm{B}$ followed by phenotype $\mathrm{A}$ than other phenotypes (mean HOMA-IR was 5.88 $\pm 3.46,6.60 \pm 3.07$, $3.98 \pm 3.81 \& 3.35 \pm 2.68$ in phenotypes A, B, C \& D respectively with $P$ value 0.018 ).

Table 3 shows comparison of different glycemic status and insulin resistance in PCOS phenotype which indicates comparable frequency of prediabetes and diabetes in PCOS phenotypes (frequency of prediabetes in phenotypes A, B, C $\&$ D were $25 \%, 33.33 \%, 16.67 \% \& 5.56 \%, P 0.247$ and DM $9.09 \%, \quad 8.33 \%, \quad 16.67 \% \& 5.56 \%, P \quad 0.871$ respectively). Overall fasting hyperinsulinaemia (as measured fasting insulin level $\geq 20 \mu \mathrm{IU} / \mathrm{ml})$ was present 43 cases $(53.75 \%)$ and its frequency was more common in phenotypes A \& B than phenotypes C \& D $(65.9 \%, 66.67 \%, 33.33 \%$ \& $22.22 \%$ respectively, $P$ value 0.009$)$. Insulin resistance as measured by HOMA-IR $\geq 3.8$ was more frequent in phenotype A \& B than phenotypes C \& D $(72.73 \%, 83.33 \%, 33.33 \% \& 27.28 \%$ respectively with $\mathrm{P}$ value 0.002$)$. Overall frequency of insulin resistance was $61.25 \%$ (49 cases).

Table 3. Glycemic status and insulin resistance in PCOS phenotypes.

\begin{tabular}{|c|c|c|c|c|c|c|}
\hline \multirow{2}{*}{ Characteristics } & \multicolumn{2}{|l|}{ All PCOS } & \multicolumn{4}{|c|}{ PCOS Phenotypes } \\
\hline & $(n=80)$ & $A(n=44)$ & $B(n=12)$ & $C(n=06)$ & $D(n=18)$ & $P$ \\
\hline Prediabetes & $17(21.25 \%)$ & $11(25 \%)$ & $4(33.33 \%)$ & $1(16.67 \%)$ & $1(5.56 \%)$ & 0.247 \\
\hline DM & $7(8.75 \%)$ & $4(9.09 \%)$ & $1(8.33 \%)$ & $1(16.67 \%)$ & $1(5.56 \%)$ & 0.871 \\
\hline $\begin{array}{l}\text { Fasting } \\
\text { hyperinsulinemia }\end{array}$ & $4(53.75 \%)$ & $29(65.9 \%)$ & $8(66.67 \%)$ & $2(33.33 \%)$ & $4(22.22 \%)$ & 0.009 \\
\hline Insulin resistance & $46(61.25 \%)$ & $32(72.73 \%)$ & $10(83.33 \%)$ & $2(33.33 \%)$ & $5(27.28 \%)$ & 0.002 \\
\hline
\end{tabular}

*Glucose intolerance includes both prediabetes and DM

†Fasting hyper insulinemia was considered when fasting insulin level $\geq 20 \mu \mathrm{IU} / \mathrm{ml}$, insulin resistance was considered when HOMA-IR $\geq 3.8$.

** $P<0.05$ indicates significant difference among the phenotypes

\section{Discussion}

Polycystic ovary syndrome is a heterogeneous disorder affecting predominantly women of reproductive age. This study was conducted to observe and compare the different metabolic components among the various phenotypes of PCOS and to observe the frequency of insulin resistance among them.

In this study, phenotypic distribution of PCOS named phenotype $\mathrm{A}(\mathrm{O}+\mathrm{H}+\mathrm{p})$, phenotype $\mathrm{B}(\mathrm{O}+\mathrm{P})$, phenotype $\mathrm{C}$ $(\mathrm{P}+\mathrm{H})$ and phenotype $\mathrm{D}(\mathrm{P}+\mathrm{O})$ were $55 \%, 15 \%, 7.5 \%$, and $22.5 \%$, respectively. Most common phenotype was A followed by $\mathrm{D}$ and phenotype $\mathrm{C}$ was least common phenotype. This finding is supported by some previous studies done in this region. $[16,17]$

In this study, mean body mass index (BMI) of all study subjects was $26.55 \pm 5.30 \mathrm{~kg} / \mathrm{m}^{2}$ and most of the patients were either overweight or obese (total $72.50 \%$ ). This finding is supported by many studies which indicated relatively higher BMI in PCOS subjects. [18] It is well documented that PCOS women have a high prevalence of abdominal body fat distribution, even if they are normal-weight, making them more vulnerable to obesity related health problems like diabetes, hypertension and cardiovascular disorders. [19] In the present study, the mean waist to hip ratio was $0.94 \pm 0.08$. This result is consistent with study done by Haider $\mathrm{S}$ et al. 2014 which also showed higher waist to hip ratio in PCOS women, even among lean group, suggesting preferential abdominal fat deposition in these patients. [18] Nowadays, waist circumference (WC) and waist-hip ratio (WHR) is considered to be more sensitive indicator for central obesity. On group analysis, hyperandrogenic phenotypes specially phenotypes A \& B had higher BMI, WC \& WHR in comparison to normoandrogenic phenotype (phenotype D) which is supported by Zhang HY et al. 2009, Sobti S et al. 2017 and Sachdeva G et al. 2019. [20-22] In contrast to this finding, some studies observed no significant difference among the phenotypes. [17, 23, 24] Different race/ethnicity, sample size and responders may be a possible causes of this variation.

Finding did not find significant difference among the phenotypes. [17, 23, 24] Different race/ethnicity, sample size and responders may be a possible causes of this variation.

As PCOS is associated with insulin resistance, significant proportion of PCOS patients may have various metabolic complications like glucose intolerance, diabetes mellitus (DM) and dysIpidemia. In this study, 30\% patients had some degree of glucose intolerance where $8.75 \%$ had frank diabetes. Higher frequency of glucose intolerance and DM in PCOS had also found by numerous studies. [17, 25-27] On group analysis, relatively higher frequency of prediabetes and DM were found in hyperandrogenic phenotypes than normoandrogenic phenotype, although significant differences were not found among the groups. Sultana T et al. 2018 also found no significant difference among the phenotypes in respect to frequency of prediabetes or DM which supports our result. [17] Like glucose intolerance, dyslipidemia is also very common in PCOS. [28-31] In this study, very high frequency (66.25\%) 
of dyslipidemia was found. Highest level of fasting TG and lowest level of HDL-C were found in complete phenotype (phenotype A) followed by phenotype B \& least in normoandrogenic phenotype (phenotype D) and significant differences were found among them which is supported by different studies. [20-22] Phenotypes A \& B had higher BMI \& WHR witch are associated with central obesity and poor insulin sensitivity; so may be associated with lower HDL-C \& higher TG. However, some studies did not find any difference among these lipid parameters. [17, 24] This study did not find any difference among PCOS phenotypes in respect to total cholesterol and LDL-C which is also suggested by some other studies. [17, 24]

Insulin resistance (IR) is a key factor for development of PCOS as well as its metabolic complications. The prevalence of insulin resistance (IR) in PCOS patients varies in different studies. It is ranges from 44 to $70 \%$. [7, 10] This wide variation may be due to different race/ethnicity, different selection criteria of PCOS and different methods used to detect IR. [7, 32, 33] There is no universal accepted method to measure IR. Different types of methods like Hyperinsulinemic Euglycemic Clamp, Frequently Sampled Intravenous Glucose Tolerance Test (FSIGT) Minimal Model Method, Oral Glucose Tolerance Test (OGTT), Homeostasis Model Assessment (HOMA), Quantitative Insulin Sensitivity Check Index (QUICKI), Fasting Insulin Level, Glucose Insulin Ratio etc. can be used for measuring IR. [34] Hyperinsulinemic Euglycemic Clamp is considered as gold standard method for insulin sensitivity. $[35,36]$ It is labor intensive, technically difficult to perform and expensive; so it is cannot be used practically. HOMA -IR is relatively easy method which has good concordance with Hyperinsulinemic Euglycemic Clamp. [15, 37] So, we had used it for measuring IR. Some other methods are also widely used for this purpose including fasting insulin level and fasting glucose to insulin ratio. IR can be diagnosed when fasting plasma insulin $\geq 20 \mu \mathrm{u} / \mathrm{ml}$ and/or fasting glucose/insulin ratio $\leq 4.5$ and/or homeostatic model assessment of insulin resistance (HOMA-IR) $\geq 3$.8. [38] In this study, mean value of fasting insulin was highest in phenotype B \& A and least in phenotype D and significant difference was present among the groups. Same type of result was also found in Zhang HY et al. 2009. [20] Highest level of fasting insulin in phenotype A followed by phenotype B and other phenotypes were found in some other studies. [21, 22] In contrast to these findings, some studies like Kar S et al. 2013 \& Pikee S et al. 2016 did not observe any difference among the phenotypes regarding fasting insulin level. [16, 24] Frequency of fasting hyperinsulinaemia (fasting insulin level $\geq 20 \mu \mathrm{IU} / \mathrm{ml}$ ) was highest in phenotype B (66.67\%) followed by phenotype A (65.9\%), phenotype C (33.33\%) and phenotype D (22.22\%). Like our finding, Pikee S et al. 2016 also observe highest fasting hyperinsulinemia in phenotype $\mathrm{B}$ followed by phenotype A. [24] Percentage of women with deranged fasting glucose-to-insulin ratio (as defined as GIR $\leq 4.5$ ) were higher in phenotype A \& B than C \& D. Lowest mean value of fasting glucose to insulin ratio was found in phenotype $\mathrm{B}$ followed by A, C \& D. In contrast to our result, Sultana T et al. 2018 found most deranged GIR in phenotype A. [17] In this study, HOMA-IR $\geq 3.8$ was selected for measuring IR and overall Insulin Resistance (IR) was $61.25 \%$. IR was found $42.6 \%$ and $66 \%$ in previous studies in this region by same cut off value of HOMA-IR by Sultana et al. 2018 \& Jamil et al. 2015. [17, 39] Definite cut off value of HOMA-IR is not well established. Using a cutoff of 3.8 may under estimate the true prevalence of IR. [40, 41, 42] Higher frequency of IR may be detected if lower HOMA-IR cut off value is selected which is proved by many observations. If HOMA-IR cut off value selected as 2.5 which is suggested by some studies, [43] IR rise to $76.25 \%$. Higher frequencies of IR were found in phenotype B (83.25\%) and phenotype A (72.67\%) than phenotype C (33.33\%) and phenotype D (27.78\%). In contrast to our finding, some studies found highest frequency of IR in phenotype A followed by phenotype B and other phenotypes. [17, 21-23] However, Welt et al. 2006 and Panidis et al. 2012 observed insulin resistance was most common in phenotype B than other phenotypes which support our result [44, 45] Genetic variations, different ethnicity, different lifestyle, environmental factors and variation in inclusion criteria may be the cause of this variation.

\section{Limitations}

This study had some limitations. Insulin resistance was detected by HOMA-IR instead of hyperinsulinemic euglycemic clamp which is the gold standard test. The sample size was small and samples were collected in a single tertiary level hospital. So this study may not represent general population. Age and BMI matched control group was not included in this study. A large scale study in different area with a proper control group should be conducted before making a definite conclusion.

\section{Conclusions}

This study reveals most common forms of PCOS are phenotype A (anovulation + hyperandrogenism + PCO) and phenotype D (ovulatory dysfunction with PCO without hyperandrogenism). Hyperandrogenic phenotypes specifically phenotype A and phenotype B has high insulin resistance, hyperinsulinaemia and hyperandrogenaemia compared to other phenotypes and so has greater cardiometabolic risks. This study also reveals normoandrogenic phenotype has least metabolic risks. Therefore, it can be recommended that screening of metabolic abnormalities should be done in all PCOS women specially hyperandrogenic phenotypes which have long term impact on health.

\section{References}

[1] Azziz R, Carmina E, Chen Z, Dunaif A, Laven JS, Legro RS, et al. Polycystic ovary syndrome. Nat Rev Dis Primers 2016; 2: 16057. 
[2] Zawadzki JK, Dunaif A. Diagnostic criteria for polycystic ovary syndrome: towards a rational approach. In: Dunaif AGJ, Haseltine F (eds) Polycystic Ovary Syndrome. Boston: Blackwell Scientific. 1992; 377-384.

[3] Rotterdam ESHRE/ASRM- Sponsored PCOS Consensus Workshop Group. Revised 2003 consensus on diagnostic criteria and long-term health risks related to polycystic ovary syndrome (PCOS). Hum Reprod 2004; 19: 41-47.

[4] Moran L, Teede H. Metabolic features of the reproductive phenotypes of polycystic ovary syndrome. Human Reproduction Update 2009, 15 (4), 477-488.

[5] Dunaif A. Insulin resistance and the polycystic ovary syndrome: mechanism and implications for pathogenesis. Endocr Rev 1997; 18: 774-800.

[6] Ford ES. The metabolic syndrome and mortality from cardiovascular disease and all-causes: findings from the National Health and Nutrition Examination Survey II Mortality Study. Atherosclerosis 2004; 173: 309-314.

[7] Diamanti-Kandarakis E, Dunaif A. Insulin resistance and the polycystic ovary syndrome revisited: an update on mechanisms and implications. Endocr Rev 2012; 33: 9811030.

[8] Amato MC, Vesco R, Vigneri E, Ciresi A, Giordano C. Hyperinsulinism and polycystic ovary syndrome (PCOS): role of insulin clearance. J Endocrinol Invest 2015; 38: 1319-1326.

[9] Polak K, Czyzyk A, Simoncini T, Meczekalski B. New markers of insulin resistance in polycystic ovary syndrome. J Endocrinol Invest 2017; 40: 1-8.

[10] Vigil P, Contreras P, Alvarado JL, Godoy A, Salgado AM, Cortes ME. Evidence of subpopulations with different levels of insulin resistance in women with polycystic ovary syndrome. Hum Reprod 2007; 22 (11): 2974-80.

[11] Norman RJ, Hague WM, Masters SC, Wang XJ. Subjects with Polycystic ovaries without hyperandrogenaemia exhibit similar disturbances in insulin and lipid profiles as those with Polycystic ovary syndrome. Hum Reprod 1995; 10: 22582261.

[12] Ferriman D, Gallway JD. Clinical assessment of body hair growth in women. Journal of Clinical Endocrinology 1961; 21: 1440-1447.

[13] American Diabetes Association. Standards of Medical Care in Diabetes -2016: Summary of Revisions. Diabetes Care 2016 Jan; 39 (Supplement 1): S4-S5.

[14] Expert Panel on Detection, Evaluation, and Treatment of High Blood Cholesterol in Adults: Executive summary of the Third Report of the National Cholesterol Education Program (NCEP) Expert Panel on Detection, Evaluation, and Treatment of High Blood Cholesterol in Adults (Adult Treatment Panel III). JAMA 285: 2486-2497, 2001.

[15] Matthews DR, Hosker JP, Rudenski AS, Naylor BA, Treacher DF, Turner RC. Homeostasis model assessment: insulin resistance and beta-cell function from fasting plasma glucose and insulin concentrations in man. Diabetologia 1985; 28: 412-419.

[16] Kar S. Anthropometric, clinical \& metabolic comparison of four Rotterdam PCOS phenotypes - a prospective study. J Hum Reprod Sci 2013; 6 (3): 194-200.
[17] Sultana T, Banu H, Akhtar N, Shah S, Zamila BM, Begum A, et al. Metabolic Disorders among Phenotypes of Polycys c Ovary Syndrome. Int J Endocrinol Metab Disord 2018; 4 (2): dx.doi.org/10.16966/2380-548X.151.

[18] Haider S, Mannan N, Khan A, Quraishi MA. Influence of Anthropometric Measurements on Abnormal Gonadotropin Secretion in Women with Polycystic Ovary Syndrome. Journal of the College of Physicians and Surgeons Pakistan 2014; 24 (7): 463-466.

[19] Kirchengast S, Huber J. Body composition characteristics and body fat distribution in lean women with polycystic ovary syndrome. Hum Reprod 2001; 16: 1255-60.

[20] Zhang HY, Zhu FF, Xiong J, Shi XB, Fu SX. Characteristics of different phenotypes of polycystic ovary syndrome based on the Rotterdam criteria in a large-scale Chinese population. BJOG. 2009; 116 (12): 1633-9.

[21] Sobti S, Dewan R, Ranga S. Metabolic syndrome and insulin resistance in PCOS phenotypes. Int J Reprod Contracept Obstet Gynecol 2017; 6: 5067-73.

[22] Sachdeva G, Gainder S, Sur V, Sachdeva N, Chopra S. Comparison of the different PCOS phenotypes based on clinical, metabolic, and hormonal profile, and their response to clomiphene. Indian J Endocr Metab 2019; 23 (3): 326-331.

[23] Baldani DP, Skrgatić L, Simunić V, Zlopasa G, Canić T, Trgovcić I. Characteristics of different phenotypes of polycystic ovary syndrome based on the Rotterdam criteria in the Croatian population. Coll Antropol 2013 Jun; 37 (2): 477-82.

[24] Pikee S, Shivani S, Jayshree B. Endocrine and Metabolic Profile of Different Phenotypes of Polycystic Ovarian Syndrome. J Obstet Gynaecol India 2016 Oct; 66 (Suppl 1): 560-566.

[25] Ehrmann DA, Barnes RB, Rosenfield RL, Cavaghan MK, Imperial J. Prevalence of impaired glucose tolerance and diabetes in women with polycystic ovary syndrome. Diabetes Care 1999; 22: 141-146.

[26] Legro RS, Kunselman AR, Dodson WC, Dunaif A. Prevalence and predictors of risk for type 2 diabetes mellitus and impaired glucose tolerance in polycystic ovary syndrome: a prospective, controlled study in 254 affected women. J Clin Endocrinol Metab 1999, 84, 165-9.

[27] Majumdar A, Singh TA. Comparison of clinical features and health manifestations in lean vs. obese Indian women with polycystic ovarian syndrome. J Hum Reprod Sci 2009 Jan-Jun; 2 (1): $12-17$.

[28] Legro RS, Kunselman AR, Dunaif A. Prevalence and predictors of dyslipidemia in women with polycystic ovary syndrome. Am J Med 2001; 111: 607-613.

[29] Diamanti-Kandarakis E, Papavassiliou AG, Kandarakis SA, Chrousos GP. Pathophysiology and types of dyslipidemia in PCOS. Trends Endocrinol Metab 2007 Sep; 18 (7): 280-5.

[30] Kim JJ, Choi YM. Dyslipidemia in women with polycystic ovary syndrome. Obstet Gynecol Sci 2013 May; 56 (3): 137142 .

[31] Kiranmayee D, Kavya K, Himabindu Y, Sriharibabu M, Madhuri GL, Venu S. Correlations between anthropometry and lipid profile in women with PCOS. J Hum Reprod Sci 2017; 10: 167-72. 
[32] Ciampelli M, Leoni F, Cucinelli F, Mancuso S, Panunzi S, De Gaetano A, et al. Assessment of Insulin Sensitivity from Measurements in the Fasting State and during an Oral Glucose Tolerance Test in Polycystic Ovary Syndrome and Menopausal Patien. The Journal of Clinical Endocrinology \& Metabolism 2005 March; 90 (3): 1398-1406.

[33] Shaw LJ, Bairey Merz CN, Azziz R, Stanczyk FZ, Sopko G, Braunstein GD et al. Postmenopausal women with a history of irregular menses and elevated androgen measurements at high risk for worsening cardiovascular event-free survival: results from the National Institutes of Health- National Heart, Lung, and Blood Institute sponsored women's ischemia syndrome evaluation. J Clin Endocrinol Metab 2008; 93 (4): 1274-84.

[34] Trout KK, Homko G, TKacs NC. Methods of Measuring Insulin Sensitivity. Biological Research for Nursing 2007 April; 8 (4): 305-318.

[35] Gungor N, Saad R, Janofsky J, Arslanian MD. Validation of surrogate estimates of insulin sensitivity and insulin secretion in children and adolescents. Journal of Pediatrics 2004; 144: 47-55.

[36] Uwaifo GI, Parikh SJ, Keil M, Elberg J, Chin J, Yanovski JA. Comparison of insulin sensitivity, clearance, and secretion estimates using euglycemic and hyperglycemic clamps in children. Journal of Clinical Endocrinology \& Metabolism 2002; 87: 2899-2905.

[37] Skrha J, Hass T, Sindelka G, et al. Comparison of the insulin action parameters from hyperinsulinemic clamps with homeostasis model assessment and QUICKI indexes in subjects with different endocrine disorders. J Clin Endocrinol Metab 2004; 89: 135-141.

[38] Legro RS, Castracane VD, Kauffman RP. Detecting insulin resistance in polycystic ovary syndrome: Purposes and pitfalls. Obstet Gynecol Surv 2004; 59: 14154.
[39] Jamil AS, Shahla KA, Al-Tawil NG, Al-Shawaf T. A casecontrol observational study of insulin resistance and metabolic syndrome among the four phenotypes of polycystic ovary syndrome based on Rotterdam criteria. Reproductive Health 2015; $12: 7$.

[40] Lebovitz HE. Insulin resistance: Definition and consequences. Exp Clin Endocrinol Diabetes 2001; 109 Supp1 2:S135 48.

[41] Bonora E, Targher G, Alberiche M, Bonadonna RC, Saggiani F, Zenere MB. Homeostasis model assessment closely mirrors the glucose clamp technique in the assessment of insulin sensitivity: Studies in subjects with various degrees of glucose tolerance and insulin sensitivity. Diabetes Care 2000; 23: 57 63 .

[42] Mather K. Surrogate measures of insulin resistance: Of rats, mice and men. Am J Physiol Endocrinol Metab 2009; 296:E398 9

[43] Singh Y, Garg MK, Tandon N, Marwaha RK. A study of insulin resistance by HOMA-IR and its cut- off value to identify metabolic syndrome in urban Indian adolescents. J Clin Res Pediatr Endocrinol 2013; 5: 245-51.

[44] Welt CK, Gudmundsson JA, Arason G, et al. Characterizing discrete subsets of polycystic ovary syndrome as defined by the rotterdam criteria: the impact of weight on phenotype and metabolic features. J Clin Endocrinol Metab 2006; 91 (12): 4842-8.

[45] Panidis D, Tziomalos K, Misichronis G, Papadakis E, Betsas G, Katsikis I, Macut D. Insulin resistance and endocrine characteristics of the different phenotypes of polycystic ovary syndrome: a prospective study. Hum Reprod 2012 Feb; 27 (2): 541-9. 